\title{
The Two Pandemics: the Disparate Impact of the COVID-19 Pandemic and the K-Shaped Recovery
}

\author{
E. Delavega ${ }^{1}$ - J. Meiman ${ }^{1}$ - C. C. Malone ${ }^{1} \cdot$ M. Hirschi ${ }^{1}$ - A. L. Hunter ${ }^{1}$. \\ S. L. Neely-Barnes ${ }^{1}$ (D)
}

Accepted: 13 February 2022 / Published online: 25 February 2022

(c) The Author(s), under exclusive licence to Springer Nature Switzerland AG 2022

\begin{abstract}
When Covid-19 appeared in the USA at the beginning of 2020, there was no treatment or vaccine. The only way to deal with the virus was containment, which resulted in business and agency closures. The impact on the economy was enormous, particularly on the lives of minorities and financially vulnerable people. The present study investigated the impact of COVID-19 on the lives of vulnerable people through qualitative interviews of major social service and healthcare agencies. The results show how the pandemic furthered existing disparities in access to a variety of services and supports.
\end{abstract}

Keywords COVID-19 $\cdot$ Disparities $\cdot$ Access $\cdot$ K-shaped recovery $\cdot$ Impact

COVID-19 started as a novel virus in late 2019, but by March 2020 had become a pandemic of unprecedented proportions (Rothan \& Byrareddy, 2020; Sorhabi et al., 2020). At the time of this study, the emergence of the virus that causes COVID-19

J. Meiman and A.L. Hunter are student authors.

S. L. Neely-Barnes

snlybrns@memphis.edu

E. Delavega

mdlavega@memphis.edu

J. Meiman

jcmeiman@memphis.edu

C. C. Malone

ccmalone@memphis.edu

M. Hirschi

mhirschi@memphis.edu

A. L. Hunter

lhunter1@memphis.edu

1 School of Social Work, University of Memphis, 226 McCord Hall, Memphis, TN 38152, USA 
was so recent that its long-term effects were still unknown. Due to its lethality and lack of a cure or a vaccine, the only manner in which the community could deal with the virus was containment (Rothan \& Byrareddy, 2020; Sorhabi et al., 2020). Months into the pandemic, businesses, organizations, social service agencies, and schools faced the enormous challenge of continuing to offer services amidst rising and falling virus transmission rates, stay-at-home orders, and phases of reopening. It is essential to understand the challenges and opportunities as well as gaps in services presented by the crisis, particularly as they affected racial and ethnic minorities, low-income people and people living in poverty, and other vulnerable populations in the USA.

\section{Conceptual Framework}

The purpose of this article is to present the results of qualitative interviews showing the differential impact of the COVID-19 pandemic on different groups of people, including service users and social service employees. While the impact of the virus itself highlighted our common humanity, the pandemic affected people differently based on social structures (Gould \& Wilson, 2020). The research originally intended to study how the emerging and fluid situation affected social service agencies in the region (see Neely-Barnes et al., 2021), as requested by community leaders, but the findings shed light on how disadvantaged people were further marginalized. Participants repeatedly shared how low-income people and minorities were particularly negatively affected by the pandemic and the response to the pandemic.

\section{COVID 19 and Impact on Employees and Clients of Social Service Agencies}

The impact of the COVID-19 crisis on social service agencies, on their employees, and their clients (service users) was significant. Agencies were tasked with the challenge of maintaining services in an ever-shifting environment requiring them to expand, change, or create new services (Gregori \& Perino, 2020). The Centers for Disease Control (CDC) emphasized that community-based organizations played an important and vital role in supporting communities during the pandemic, with the ability to link community members to essential health or social services (CDC, 2020a). Social service agencies were uniquely positioned to gain insight about what resources were needed during the crisis and about how the crisis impacted their clients or service users (CDC, 2020a; Gregori \& Perino, 2020).

As a result of the COVID-19 pandemic, social service agencies faced challenges in service-delivery models that while innovative, may have negatively impacted both employees and clients (Dey et al., 2020; Jones, 2015; Lister \& Harnish, 2011). There are many goods or services that social service organizations must deliver in person, such as food, medical services, or residential support; the COVID 19 crisis disrupted these services at least initially, creating challenges around service delivery (Barney et al, 2020; Dey et al., 2020; Gould \& Shierholz, 2020) and thus impacting vulnerable clients. Many jobs may not be performed from home, and these are 
usually done by low-wage workers (Dey et al., 2020; Gould \& Shierholz, 2020), even in agencies that may have been able to allow many workers to work remotely. Social distancing rules that limited the number of client agencies may have been able to serve, and this led to reduced services (Barney et al, 2020; Dey et al., 2020; Gould \& Shierholz, 2020).

\section{COVID 19 and Impact on Population}

The full impact of the COVID-19 crisis on the general population was not yet known at the time the authors wrote this article, but undoubtedly will have far-reaching economic, social, and health-related implications, particularly for low-income people and people living in poverty. The most vulnerable populations-senior citizens, people of color, low-income or unemployed citizens, homeless people, and immigrants-experience the most significant impact of systemic inequality, requiring focused attention on public policies that either mitigate or exacerbate its effects (Reeves \& Rothwell, 2020; Weible et al., 2020; Wright \& Merritt, 2020). Lowincome people are much more vulnerable to the COVID-19 virus due to a combination of factors, including lack of access to healthcare, work in high-exposure jobs, living conditions that make social distance difficult to impossible, and high levels of comorbidities (Reeves \& Rothwell, 2020).

Historically, racial and ethnic minorities have always been at higher health risks during public health crises and therefore have a statistically higher risk of contracting COVID-19 (CDC, 2020b, 2021; Gould \& Wilson, 2020). Social determinants including poverty-related living conditions, working conditions, and public health circumstances put these groups at higher risk and leave them vulnerable to negative health outcomes (CDC, 2020b; Ebor et al., 2020; Ford et al., 2020; Gould \& Wilson, 2020; Reeves \& Rothwell, 2020). Disparities in the social, economic, and healthcare system in the USA have resulted in differences in how people have been impacted by the virus at all points along the exposure-disease-death continuum. African Americans and other minorities have suffered disproportionately from this disease (CDC, 2020b, 2021). The CDC reported that "identified death rates among black/African American persons (92.3 deaths per 100,000 population) and Hispanic/Latino persons (74.3) were substantially higher than that of white (45.2) or Asian (34.5) persons" (2020). The increased disease and death rates experienced by minority groups were also linked to poverty (APM Research Lab, 2020; Reeves \& Rothwell, 2020).

\section{Existing Social Issues, Magnified}

Minorities and people in poverty already experienced food insecurity, lack of transportation, difficulties paying affordable rent, lack of access to the internet, etc. before COVID-19 hit (Gould \& Wilson, 2020; Long et al., 2020). These problems were not brought on by the pandemic, but they were magnified by it (Gould \& Wilson, 2020; Long et al., 2020). While people who were able to continue to work from home remained financially secure, people working in the service sector who could not work 
from home experienced job loss and a slower recovery (Long, 2020). The health, social, and economic impacts of COVID-19 have been enormous and felt at all levels. Social distancing was often a privilege for those with moderate or higher incomes, because those jobs are more likely to afford the opportunity to work from home, whereas people in lower income jobs may have less opportunity to avoid contact by not reporting to a workplace (Barney et al., 2020; Papanikolaou \& Schmidt, 2020; Weible et al., 2020; Yancy, 2020). Essential workers are those workers who due to the nature of the work were required to be in the workplace and on the frontlines during the pandemic which placed them at risk, but not all have the same status or power to protect themselves, revealing significant inequities in the work force (Glover et al., 2020; Miller et al., 2020; Van Drie \& Reeves, 2020). Furthermore, many low-wage workers work in the service industry and not only were not able to avoid the workplace, but may not even have been able to socially distance at all as these jobs require close contact (Gould \& Shierholz, 2020). The lack of childcare during the pandemic also placed additional burdens on these workers (Gould \& Shierholz, 2020).

The lack of access to healthcare created yet another obstacle for at-risk populations dealing with COVID-19. Low-income people who do not qualify for Medicaid typically have limited opportunities for employer-based health insurance coverage under the Affordable Care Act and thus are uninsured (Allen \& Sommers, 2020; Garfield et al., 2020). Those who are uninsured and encounter a need for medical care may face deep financial challenges unless there is an expansion in ACA Medicaid coverage throughout the USA (Allen \& Sommers, 2020; Garfield et al., 2020). Furthermore, there is the issue of access to the technology required for telehealth and telemedicine services, and people of lower socioeconomic status living in "digital deserts" may not have access to the internet needed for telehealth (Beaunoyer et al., 2020). Currently, vast inequalities in digital access remain, and the impact of this divide may have put low-income people at greater risk of both COVID-19 disease and less opportunity to obtain help due to the inability to access online health information, utilize digital alternatives to in-person services, or obtain adequate healthcare via telehealth (Beaunoyer et al., 2020).

As a result of the above, social service agencies may have experienced both a reduction in resources (economic and human), and an increase in the need for services, with the additional challenges posed by the necessary hygienic precautions recommended by the Centers for Disease Control (CDC) (2020a). This study presents the findings in terms of disparities that were found through interviews with social service agencies. The original purpose of the interviews was to understand how the pandemic had affected social service and behavioral health agencies. The interviews shed light on how the pandemic magnified disparities and further disadvantaged marginalized groups and people in poverty.

\section{Methods}

In the spring of 2020, as the COVID-19 pandemic was ramping up, a study was designed to explore the phenomenon (Creswell, 2013; Patton, 2002) of COVID and the impact it had on different agencies in a specific region in the Southeastern United 
States. A research team based at a university School of Social Work was formed of four faculty members and two graduate students to explore this phenomenon. Institutional Review Board approval was obtained prior to conducting any human subject research.

\section{Context of Data Collection}

At the time of study design, the impact of COVID-19 was an extremely new phenomenon, and as a result, no theoretical framework was incorporated. The researchers sought to explore the first observations from agency leaders in a rapidly evolving situation. The context was different in March or April 2020 than in September 2021. In April 2020, just as the pandemic had led to an enormous number of closures and enormous uncertainty, the research team was approached by community agency leaders who wished to understand how the pandemic was affecting the social service and behavioral health industries.

The research team met to determine which agencies would be important to provide their insight and experience about the impact of COVID-19 and the work they do at the micro, mezzo, and macro levels. Drawing from the agencies affiliated with the university field education department, a list of 184 organizations was used. From these agencies, purposeful sampling (Miles et al., 2014; Patton, 2002) was chosen to ensure adequate representation of agency type, location, and services (see Appendix Table 1). Additionally, some snowball sampling was used to gain greater representation in rural areas. A narrowed targeted sample of 70 agencies was used. In early summer, initial email requests were sent and agencies willing to participate were sent an electronic informed consent. Respondents were directors, CEO's, founders, supervisors, and in general upper management/leadership. The researchers did not collect their demographic information as it was not deemed relevant. Broad descriptions of participant agencies are presented in Appendix Table 1. For a more detailed description of participating agencies, see Neely-Barnes et al. (2021). Upon receipt of signed consent, a graduate student was assigned to schedule and conduct the interview. Questions requesting agency demographic data were sent prior to the interview (e.g., race/ethnicity breakdown of clients, annual agency budget, number of employees). A total of 37 agencies agreed to participate in this study (see NeelyBarnes et al., 2021).

\section{Interviews}

The semi-structured interview guide included the questions designed to assess the effect the pandemic was having on social service agencies. Some of the questions included were "How have your services changed since the beginning of the COVID19 crisis?" and "What changes have you seen in your clients since the beginning of the crisis? Are you seeing more people or fewer people requesting your services?" The researchers also asked about changes to the service model, whether the request for services had increased or decreased, the barriers clients had experienced, and the responses the agency had implemented to emerging challenges. The administrative 
and organizational challenges and solutions experienced by participating agencies are detailed in Neely-Barnes et al. (2021).

Interviews were conducted and recorded using Zoom technology. Participants were compensated for their time with a $\$ 15$ electronic gift card. Interviews lasted approximately 30-60 min. Sonix electronic transcription service was used to generate transcripts from Zoom recordings. All transcripts were verified for accuracy by the interviewer. Research team meetings were held on a weekly basis during the preparation and interview phase of the project. To maintain consistency across interviews, all interviews were conducted by the graduate student researchers. After the first 2-3 interviews were conducted by each graduate student researcher, the interview guide and process were discussed by the full team and minimal adjustments were made to enhance the flow of the interview and clarity of the questions. As part of this process, faculty researchers also selected recordings to view in order to maintain consistency and strengthen internal validity (Miles et al., 2014). As more interviews were conducted, graduate student researchers each randomly selected five transcripts from the other to verify.

\section{Analysis}

Using Creswell's (2013) five step approach to phenomenological analysis, all interview data were analyzed. One, data were organized and themes were discussed in regular meetings in order to develop an initial coding structure. The NVivo qualitative software was also used to help with organization and analysis. Two, all six research team members read and memoed initial transcripts. Team members were then divided into pairs and two agencies were assigned to each pair for initial coding. Upon completion of initial coding, the research team met to discuss the codes. Adjustments were made to the coding structure and analysis continued. Three, describing and classifying themes took place during the main round of coding. All codes were discussed to maximize internal consistency of coding across all researchers. The remaining interviews were coded by pairs of researchers who rotated to strengthen consistency of coding across all data. Four, the data were interpreted upon completion of all coding. Content analysis was used to examine the data carefully to explore emerging themes. For the purposes of this article, data were analyzed in terms of impact for different social and demographic groups, such as service users or workers. Comments addressing income or race were particularly noted. Five, representing the data was done by pulling out selected quotes to represent themes. These are presented in the results section below.

\section{Results}

Given the variety of populations served by the agencies in the study, issues relating to social justice were broad and intersectional. Disparities in access - access to services, education, transportation, and most notably, technology - weighed the most heavily throughout the interviews, for both the clients and the workers of such 
agencies. The themes that emerged identify very disparate experiences for populations in with low incomes and higher incomes. The researchers report these findings because even though race and income were not specific elements in the questions asked, race and income issues were brought up by respondents again and again. We organize our findings first in two broad themes focusing on the impact of the pandemic on those whom agencies serve (Impact on Clients or Service Users) and the impact of the pandemic on the workers serving within the agency (Impact on Employees). Under the Impact on Clients theme, the following subthemes are identified: (a) Need for Services and/or Resources, (b) Access to General Services and/ or Resources, (c) The Digital Divide, (d) Transportation as a Barrier to Access, and (e) Disparate Racial Impact. Under the Impact on Employees theme, we identify the following subthemes: (a) Work and Working Conditions and (b) Childcare. Under each of these themes and subthemes, we discuss the disparities we found between people with low incomes and higher incomes. The results show that those on the lower end of the economic spectrum were (and are) living in a completely different reality as those with higher statuses and more economic means.

\section{Impact on Clients}

\section{Need for Services and/or Resources}

Respondents repeatedly talked about the increase in need they were seeing as a result of the pandemic. In general, respondents reported an increase in need for food and other resources due to job losses and the economic crisis. It was typical that social service agencies of all sizes reported an increase in need, particularly of basic needs. A large agency serving the poor said,

Our food pantry has increased significantly from, you know, we were serving about 60 or so a month at the food pantry, and I think our highest month was April and we served one hundred and forty households. So it doubled, more than doubled.

Respondents were clear that poverty is nothing new, and the community had been fighting it for a while, but the level of need was increased as people who had not previously needed assistance were now requiring assistance:

There was a woman that said, you know, I never thought I would be here.

There was a general feeling that the gains made in the past few years were wiped by the pandemic. People who had worked hard towards self-sufficiency had lost all the gains of the previous years. The director of a community school reported the effects of the pandemic on poor people:

Some may have lost jobs and have some have had to stop working forcefully because their children may have you know, that, of course, their children had to stay home. So, they may not have had support from family members like a lot of other people have, where they can send their child to someone else's house, while they continue to go to work. 


\section{Access to General Services and/or Resources}

Both the COVID-19 restrictions and the resulting economic crisis created barriers for access. Some of the COVID-19 restrictions that created barriers to access included agency closures, school closures, lack of access to the internet, and limits on transportation. The economic crisis impacted people through job losses, which often resulted in the loss of medical insurance and other barriers to access, such as funding losses or restrictions. One agency described how preexisting funding restrictions exacerbated the effect of the pandemic by limiting the help that could be offered under the unique conditions of the pandemic:

Right now, we've got someone on the other side of the state who has tested positive for COVID19 and has been kicked out by his roommates and they won't let them back into the apartments. And he is now homeless. We can't do anything, because our grantee has, as of right now, they have not tried to amend their consolidated plan yet to allow us to pay for a hotel for someone.

Those who were able to retain their jobs and insurance were able to continue receiving services, but those who lost their insurance were not. A behavioral/integrated healthcare agency expressed,

Our population includes people that have lost jobs as servers, have lost jobs in transportation and building. So, we have people that have lost their health insurance and can't afford to follow through [on their treatment].

The health guidelines to protect the community during the pandemic also limited the amount of services available to the most vulnerable people. The director of a homeless shelter reported that,

... social distancing requires that we that we're not able to provide the beds that we were previously. So, on many different levels we've been impacted.

People who were able to make choices, including governmental agencies, were able to modify their work to protect themselves, but that meant cutting access to the most vulnerable people. The executive director of an agency serving people with intellectual disabilities said,

We stopped going into people's homes. We stopped taking people into the community. We did a lot of evaluating change. But, you know, it pretty much brought all of our interactive services to a halt.

\section{The Digital Divide}

The digital divide as a clear issue of access was made stark by the pandemic. For those with access to computers and the internet, life and access to goods and services could continue, but for those without computers or the internet it marked a sharp removal of access. Some agencies were keenly aware of the digital divide. One agency director expressed it this way: 
this crisis [has] illuminated many injustices. And so I think within that illumination, it [has]allowed at least a window of time for some people to see that there are a range of matters of inequity. And so, the digital divide is clearly one of those. In the digital divided, you can connect to other areas of inequity, like a poor education, workforce development and not having jobs and careers available - [not making] at least fifteen dollars an hour, if not more, [not] having access to my health care without having to go into a health care provider.

\section{Transportation as a Barrier to Access}

Transportation is a large system-wide barrier for clients to access services. Prior to COVID, transportation was already inadequate (Delavega, 2014) social distancing and change in service delivery format exacerbated transportation barriers by reducing public transit capacity and making cars a requirement for receiving services. Agencies including healthcare providers and charity organizations said,

Transportation is key and the [local] transportation had reduced their load to ten. . . And so that was the first thing we saw was the decrease in volume and the consumer's ability to access their services.

Those individuals that didn't have a car to get to the food bank opportunities or were not able because those are types of things that you can't get on a bus line and go get. They are mandatory drive thru.

\section{Disparate Racial Impact}

COVID-19 is affecting low-income people and people in poverty, but also very importantly, affecting minorities in a more negative way. The racial disparities made apparent by the pandemic were made clear by the comments from several agencies serving the poor:

The people that we're serving are, you know, the ones who are bearing the load of this pandemic. They are poor. They are people of color. They are Black. And they are the ones dying at the highest rate. They are the ones losing their jobs first. They are the ones who are going to be evicted first.

Well, we have two pandemics going on. We have COVID19 and we have racism and the matters around race and racism. And they're not disconnected.

\section{Impact on Employees}

\section{Work and Working Conditions}

For those employees who were able to work remotely, work continued, and they were able to keep their jobs and benefits. For some, it was a very positive, productive experience and loved it. 
But I think that we're going to see a lot more of the alternate work site teleworking for sure, because it's worked so well, and people are happier. And when they're happier, they're more productive anyway.

The situation was not so positive for low-income workers or part-time workers, who lost their hours:

Our part time employees weren't working much at all. Because now we don't have, we don't need as many staff support staff on campus.

Low-income workers have to contend with low wages, and that is not going to be solved any time soon. Some of these workers have no choice but to work multiple jobs. A representative from a healthcare agency commented about their low-wage employees:

But that's an additional safety concern because usually those staff work other jobs, and so keeping them safe. If one of them tested positive, what would, we haven't experienced that thankfully. But what would we do? How do we quarantine them?

While another complained about workers wanting a living wage and expressed the narrative that has spurred many states to discontinue unemployment:

we do need more direct care staff and you can't get anybody to look for a job. You know, if somebody is out of work, they're not going to come look for a ten, eleven dollar an hour job when they can make more than that on unemployment right now.

\section{Childcare}

The two pandemics is clearly illustrated in the issue of childcare. Some people had resources and could stay home with their children, and this may have benefited those workers with newborns. For these employees, there were positives of working from home with children:

There are positives to this situation regarding childcare. For starters, people working from home do not need childcare. People with newborns love this time.

I don't think we've had a sick leave request in three months. So. That just says that employees are just doing what they need to do and they're not taking off.

However, those workers who were not able to stay home faced increased challenges:

I know that a lot of them struggled finding day care, because day cares were closed. 


\section{Discussion}

The results of this study are consistent with data showing the employment and consumption has affected people at both ends of the economic spectrum quite differently. This pandemic has affected low-income people in a much more severe manner than more affluent workers (Long, 2020; Long et al., 2020). In April 2020 , employment in the region fell dramatically for all groups, but while highincome workers had lost $8.1 \%$ and middle-income workers had lost $12.2 \%$ compared to their level of employment in January 2020, low-income workers had lost 25.9\% (Opportunity Insights, 2021). Furthermore, by August 2021, employment levels were for high-income workers $118.1 \%$ and for middle-income workers $99.1 \%$ what they had been in January 2020, but for low- income workers employment remained at $80.6 \%$ (Opportunity Insights, 2021). People who were able to work from home were affected less severely and recovered quickly (Long, 2020), but those who were not able to work from home were faced with either exposure to the disease or job loss. In many cases, low-wage workers did not have a chance to make a choice - their jobs simply disappeared (Long, 2020). Our findings are consistent with what has been termed a "K-shaped recovery" (Long, 2020), a situation in which disparities are increased as the wealthy recover but the poor do not and in fact have worse economic outcomes over time (Long, 2020). Social service agencies saw an increase in need while resources of all kinds became more limited and barriers to access increased. Even within the agencies, there were disparities between workers. There were those who could work from home and there were those, generally the lowest paid, who may have lost hours or not have a job at all. Other factors such as childcare, affected workers differentially as well, with some workers enjoying time at home with their children while others struggled with childcare as a result of school closures. While this may not have been true for all remote workers, those workers who were able to work remotely in situations of comfort experienced a pandemic that was boring and slightly uncomfortable, but those workers who were not able to work from home were faced with the heart-wrenching choice of starvation or exposure. Some workers simply lost their jobs and they suffered economic problems and inability to find other work, and this strained social service agencies tremendously. Transportation is another area in which the two pandemics and the disparities they highlight were visibly exposed. As some agencies moved toward the provision of services through drive-through, people without cars found themselves even more excluded and unable to receive the help and services they desperately needed.

\section{Two Pandemics in the Middle of an Endemic Plague}

This study has also highlighted the other epidemic in this country. It is a longstanding problem in this country, and very much American. It is the epidemic of racism. Rather than a pandemic, the epidemic of racism is locally endemic. 
Racism is a crisis that we have had in this country since its inception, and we continue to see the effects. The COVID-19 pandemic only served to illuminate the disparities, which clearly fall along racial lines (CDC, 2021; Gould \& Wilson, 2020). Poverty affects minorities in greater rates, and as we have seen, minorities bear the brunt of the disparities, the pain, and the higher death rates (CDC, 2021; Gould \& Wilson, 2020). This is an issue of social justice for social work. We cannot close our eyes to the pain and disparities that exist. What the two pandemics highlight by the juxtaposition of disparate outcomes is the racialized nature of poverty and of death (Gould \& Wilson, 2020). The poor and racial minorities have suffered the greatest exclusion and death (CDC, 2021; Gould \& Wilson, 2020). Social workers can work toward ending racism by educating themselves about this issue, examining their own biases and actions, advocating for disadvantaged minorities, and voting for, and supporting, anti-racist policies at local to federal levels.

\section{Limitations}

While this is a robust study that includes a large sample of diverse agencies, it is a qualitative study limited to a very localized region in the USA. Thus, the findings might not be generalizable to other parts of the USA. Study data was only collected during June and July of 2020, thus the data might not be generalizable to other parts of the pandemic, as conditions were different in April 2020, July 2020, and April 2021. Additionally, the findings presented here are the observations and perceptions of the agency leaders who responded to the interview and should be interpreted with caution as such.

\section{Ethical Implications}

The pandemic exacerbated the disparities and injustices that lie at the core of our society. Under normal circumstances, it is possible to ignore the societal conditions that allow some to have too much and many to be unable to meet their most basic needs. Under normal circumstances, social workers can pretend we are doing something to solve the problem and remain content with our little interventions. The reality of the pandemic should serve as a wake-up call and lead us to question the system that results in such disparities. The problems have always been there: People who barely eke a living and who lack the most basic social protections became woefully battered by the pandemic, but the pandemic did not bring any new conditions. It just allowed us to see what was always there.

In our desire to return to normal and things as they were, we must ask ourselves if we want to return to a world in which disparities and exclusion are allowed to fester under the surface, or whether we can use this opportunity to examine the systems that have led to a painless break for some and a brutal shakedown for others. The research team found it particularly jarring when one of the agencies reported dismay at not being able to find workers that would work in a high-risk position for 
less than what unemployment pays. The social conditions that require that workers toil for less than a living wage is unjust and should be abhorrent to social workers. We have a mandate to act for social justice (National Association of Social Workers, 2017), and it is clear that we have seen the injustice. We cannot, we must not, remain passive.

\section{Conclusion}

In the USA and throughout the world, social service agencies are tasked with providing adequate resources to the people in the ever-shifting landscape of a global pandemic. As each day passes, scientists seek to understand the virus and provide evidence-based guidance to public health initiatives, while the general population grapples with both the health-related and economic repercussions affecting daily life. As gaps in the research related to virus transmission, virus immunity, and virus impact on populations are filled, a clearer picture is emerging about the needs of the community and resources required to address the detrimental effects of COVID-19; this, in turn, will allow the social work profession to better understand the current situation and to more effectively meet the needs of the community caused by the crisis. This study attempts to contribute to the literature investigating COVID-19 and its impact on social service agencies, their employees, and the populations they serve. 


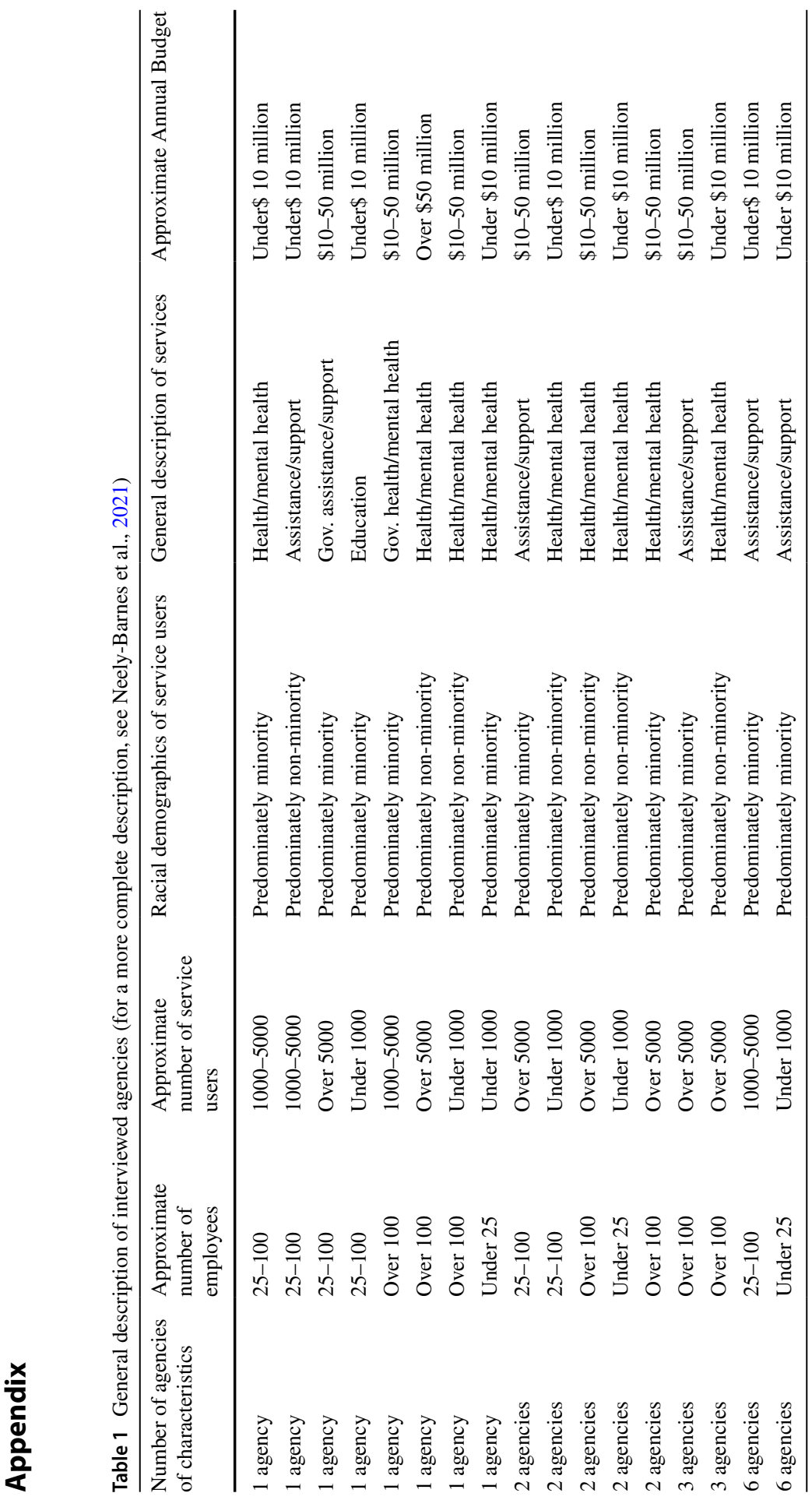


Funding This study was funded by the University of Memphis Research Foundation.

\section{Declarations}

Conflict of Interest The authors declare no competing interests.

\section{References}

Allen, H. L., \& Sommers, B. D. (2020). Medicaid and COVID-19: At the center of both health and economic crises. JAMA, 324(2), 135-136. https://doi.org/10.1001/jama.2020.10553

APM Research Lab. (2020). The color of coronavirus: COVID-19 deaths by race and ethnicity in the U.S. Retrieved from https://www.apmresearchlab.org/covid/deaths-by-race

Barney, A., Buckelew, S., Mesheriakova, V., \& Raymond-Flesch, M. (2020). The COVID-19 pandemic and rapid implementation of adolescent and young adult telemedicine: Challenges and opportunities for innovation. The Journal of Adolescent Health: Official publication of the Society for Adolescent Medicine, 10. Retrieved from https://doi.org/10.1016/j.jadohealth.2020.05.006

Beaunoyer, E., Dupéré, S., \& Guitton, M. J. (2020). COVID-19 and digital inequalities: Reciprocal impacts and mitigation strategies. Computers in Human Behavior, 111. Retrieved from https://doiorg.ezproxy.memphis.edu/https://doi.org/10.1016/j.chb.2020.106424

Centers for Disease Control [CDC]. (2020a). Coronavirus disease 2019 (COVID-19): Communities, schools, workplaces, and events: Considerations for community-based organizations. Retrieved from https://www.cdc.gov/coronavirus/2019ncov/community/organizations/community-based.html

Centers for Disease Control [CDC]. (2020b). Coronavirus disease 2019 (COVID-19): COVID-19 in racial and ethnic minority groups. Retrieved from https://www.cdc.gov/coronavirus/2019-ncov/ community/health-equity/race-ethnicity.html

Centers for Disease Control and Prevention [CDC]. (2021). COVID data tracker. Retrieved from https:// covid.cdc.gov/covid-data-tracker/\#demographics

Creswell, J. W. (2013). Qualitative inquiry \& research design: Choosing among five approaches (3rd ed.). Thousand Oaks, CA: Sage.

Delavega, E. (2014). Public transportation and earnings in Memphis. [Fact Sheet]. Retrieved from http:// www.memphis.edu/socialwork/pdfs/fact_sheets/2014memphistransportation.pdf

Dey, M., Frazis, H., Loewenstein, M. A., \& Sun, H. (2020). Ability to work from home: Evidence from two surveys and implications for the labor market in the COVID-19 pandemic. Monthly Labor Review, U.S. Bureau of Labor Statistics, June 2020. Retrieved from https://doi.org/10.21916/mlr. 2020.14

Ebor, M. T., Loeb, T. B., \& Trejo, L. (2020). Social workers must address intersecting vulnerabilities among noninstitutionalized, black, Latinx, and older adults of color during the COVID-19 pandemic. Journal of Gerontological Social Work. Retrieved from https://doi-org.ezproxy.memphis. edu/https://doi.org/10.1080/01634372.2020.1779161

Ford, T., Reber, S., \& Reeves, R. V. (2020). Race gaps in COVID-19 deaths are even bigger than they appear. Retrieved from: https://www.brookings.edu/blog/up-front/2020/06/16/ race-gaps-in-covid-19-deaths-are-even-bigger-than-they-appear/

Garfield, R., Orgera, K., \& Damico, A. (2020). The coverage gap: Uninsured poor adults in states that do not expand Medicaid. Issue brief: Henry Kaiser Family Foundation. Retrieved from: https://www. kff.org/medicaid/issue-brief/the-coverage-gap-uninsured-poor-adults-in-states-that-do-not-expandmedicaid/

Glover, R. E., van Schalkwyk, M. C., Akl, E. A., Kristjannson, E., K., Lofti, T, Petkovic, J., Petticrew, M. P., Pottie, K., Tugwell, P., Welch, V. (2020). A framework for identifying and mitigating the equity harms of COVID-19 policy interventions. Journal of Clinical Epidemiology, 128, 35-48. Retrieved from https://doi.org/10.1016/j/jclinepi.2020.06.004

Gould, E., \& Shierholz, H. (2020). Not everybody can work from home: Black and Hispanic workers are much less likely to be able to telework. Working Economics Blog. Economic Policy Institute. Retrieved from https://www.epi.org/blog/black-and-hispanic-workersare-much-less-likely-to-be-able-to-work-from-home/ 
Gould, E., \& Wilson, V. (2020). Black workers face two of the most lethal preexisting conditions for coronavirus - racism and economic inequality. Economic Policy Institute. Retrieved from https://www. epi.org/publication/black-workers-covid/

Gregori, E., \& Perino, A. (2020). The challenges of social work in the management of COVID-19. Culture e Studi Del Sociale, 5, 347.

Jones, J. (2015). In US telecommuting for work climbs to 37\%. Retrieved from http://www.gallup.com/ poll/184649/telecommuting-work-climbs.aspx

Lister, K. \& Harnish, T. (2011), The state of telework in the US. Retrieved from http://www.workshifting. com/downloads/downloads/Telework-Trends-US.pdf

Long, H. (2020). The recession is over for the rich, but the working class is far from recovered. Washington Post. Retrieved from https://www.washingtonpost.com/road-to-recovery/2020/08/13/recessionis-over-rich-working-class-is-far-recovered/

Long, H., Van Dam, A., Flowers, Al., \& Shapiro, L. (2020). The COVID-19 recession in the most unequal in modern U.S. history. Washington Post. Retrieved from https://www.washingtonpost.com/ graphics/2020/business/coronavirus-recession-equality/

Miles, M. B., Huberman, A. M., \& Saldaña (2014). Qualitative data analysis: A methods sourcebook (3rd ed.). Thousand Oaks, CA: Sage.

Miller, C. C., Kliff, S., \& Sanger-Katz, M. (2020). Avoiding coronavirus may be a luxury some workers can't afford. The New York Times. Retrieved from https://www.nytimes.com/2020/03/01/ upshot/ coronavirus-sick-days-service-workers.html

National Association of Social Workers. (2017). Code of Ethics. Retrieved from https://www.socialworkers. org/About/Ethics/Code-of-Ethics

Neely-Barnes, S. L., Hunter, A. L., Meiman, J. C., Malone, C. C., Hirschi, M., \& Delavega, E. (2021). Leaning into the crisis: Managing COVID-19 in a social services or behavioral health agency. Human Service Organizations: Management, Leadership, \& Governance, 45, 293-306.

Opportunity Insights. (2021). Percent change in employment. Retrieved from https://tracktherecovery.org/ Papanikolaou, D. \& Schmidt, L. D. W. (2020). Working remotely and the supply-side impact of COVID19. National Bureau of Economic Research, Working Paper 27330. Retrieved from http://www.nber. org/papers/w27330

Patton, M. Q. (2002). Qualitative Research and Evaluation Methods (3rd ed.). Thousand Oaks, CA: Sage.

Reeves, R. V. \& Rothwell, J. (2020). Class and COVID: How the less affluent face double risks. Brookings Institution. Retrieved from: https://www.brookings.edu/blog/up-front/2020/03/27/class-andcovid-how-the-less-affluent-face-double-risks/

Rothan, H. A., \& Byrareddy, S. N. (2020). The epidemiology and pathogenesis of coronavirus disease (COVID-19) outbreak. Journal of Autoimmunity, 109. Retrieved from https://doi.org/10.1016/j.jaut. 2020.102433

Sorhabi, C., Alsafi, Z., O’Neill, N., Khan, M., Kerwan, A., Al-Jabir, A., Iosifidis, C., \& Agha, R. (2020). World Health Organization declares global emergency: A review of the 2019 novel coronavirus (COVID-19). International Journal of Surgery, 76, 71-76. https://doi.org/10.1016/j.ijsu.2020.02.034

Van Drie, H. \& Reeves, R. V. (2020). Many essential workers are in "low-prestige” jobs. Time to change our attitudes - and policies? Retrieved from: https:/www.brookings.edu/blog/up-front/2020/05/28/ many-essential-workers-are-in-low-prestige-jobs-time-to-change-our-attitudes-and-policies/

Weible, C. M., Nohrstedt, D., Cairney, P., Carter, D. P., Crow, D. A., Durnova, A. P., Heikkila, T., Ingold, K., McConnell, A., \& Stone, D. (2020). COVID-19 and the policy sciences: Initial reactions and perspectives. Policy Sciences 53, 225-241. Retrieved from https://doi.org/10.1007/s11077-020-09381-4

Wright, J. E., \& Merritt, C. C. (2020). Social equity and COVID-19: The case of African Americans. Public Administration Review. https://doi.org/10.1111/puar.13251

Yancy, C. W. (2020). COVID-19 and African Americans. JAMA, 323(19), 1892-1892. https://doi.org/10. 1001/jama.2020.6548 